\title{
Aberrant Right Hepatic Artery: A Systematic Review
}

\author{
Dr. Chaudhari Gunwant ${ }^{1}$, Dr. Sonawane Monali ${ }^{2}$, Dr. Singel T.C ${ }^{3}$, Dr. Chaudhari Heena ${ }^{4 *}$ \\ ${ }^{1}$ Prof. and Head, Department of Anatomy, Zydus Medical College and Hospital, Dahod, Gujarat, India \\ ${ }^{2}$ Associate Professor, Department of Anatomy, Zydus Medical College and Hospital, Dahod, Gujarat, India \\ ${ }^{3}$ Professor, Department of Anatomy, Zydus Medical College and Hospital, Dahod, Gujarat, India \\ ${ }^{4}$ Assistant Professor, Department of Anatomy, Zydus Medical College and Hospital, Dahod, Gujarat, India
}

DOI: 1 10.36348/sijap.2020.v03i09.001 | Received: 19.09 .2020 | Accepted: 27.09 .2020 | Published: 30.09 .2020

*Corresponding author: Dr. Chaudhari Heena

\section{Abstract}

Abdominal arterial branching pattern have given attention to researchers because of their significance. The variations in branching pattern of hepatic artery, supplies liver are documented by many authors. But still there are much variations present which are not classified. The aim of present study was to aid the knowledge of variation in the hepatic artery for surgeons and radiologists. For this study, scientific literature from PubMed was carried out from year 2005 to 2020 for the articles having anatomical variations of the hepatic artery in all publications. The relevant articles were also studied. Out of 2173 cases, 1500 (69.02\%) showed type I normal pattern. 37 (1.70\%) cases displayed type II: a replaced LHA from left gastric artery. Type III: a replaced RHA from SMA was observed in $158(7.27 \%)$ cases. Type IV: replaced RHA and LHA were observed in $4(0.18 \%)$ cases.136 (6.25\%) cases displayed type V: an accessory LHA. 7(0.32 \%) of the subjects were found to have type VI: an accessory RHA. Type VII: accessory RHA and LHA. Type VIII: a replaced RHA or LHA with other hepatic artery being an accessory one were not found. Type IX: the hepatic trunk as a branch of the SMA were $14(0.64 \%) .1(0.04 \%)$ was found in type X: the CHA from the left gastric artery. Variations in hepatic arterial pattern are useful for various surgical procedures like hepatobiliary, pancreatic, gastric surgery and radiological interventions. Accidental ligation or injury to these vessels may interrupt the blood supply.

Keywords: Aberrant Hepatic Artery, Right hepatic artery, anomalies.

Copyright @ 2020: This is an open-access article distributed under the terms of the Creative Commons Attribution license which permits unrestricted use, distribution, and reproduction in any medium for non-commercial use (NonCommercial, or CC-BY-NC) provided the original author and source are credited.

\section{INTRODUCTION}

Abdominal arterial branching pattern have gave attention to the anatomist, surgeon and radiologist because of their significance. Common hepatic artery gives proper hepatic artery. The right hepatic artery mostly arises from the proper hepatic artery. It lies left to the common bile duct. Before it enters into the Callot's triangle, it runs upward, turn to right and lies behind the common hepatic duct. Close to cystic duct, it gives cystic artery and runs upward to enter the liver. Hepatic artery close to liver divides into anterior and posterior division. Anterior division supplies V \&VIII segment and posterior division supplies VI \&VII segment [1]. $25 \%$ of blood and $50 \%$ of oxygen is provided by the hepatic artery to the liver [2]. If the RHA does not origin from the PHA or CHA, it arise from aorta or any arteries which runs towards the right side of the aorta like superior mesenteric artery, gastroduodenal artery, right gastric artery, or celiac trunk [3] [4]. If the hepatic artery does not arise from the terminal end of celiac trunk and arise from other source, it is regarded as aberrant hepatic artery, usually present in $1 / 3$ of cases. There are two types of aberrant hepatic artery, replace artery and accessory artery. The replace artery is replacement of normal hepatic artery because hepatic artery is absent. Accessory artery is additional artery for that which is normally present [5, 6].Three hepatic arteries, (a) Left hepatic artery, (b) middle hepatic artery (c) right hepatic artery are present during the early stages of development. The left hepatic artery arises from the left gastric artery, middle hepatic artery arises from the celiac trunk and right hepatic artery arises from the superior mesenteric artery. The middle hepatic artery persists and remains as classic proper hepatic artery in the adult. The middle hepatic artery gives two branch right and left, and supply the respective hemi- lobe of liver [7]. Variation in regression and persistence of above three arteries termed as accessory and replaced variants [8].

The aim of the present study was to aid the knowledge of variation in the hepatic artery to liver transplant surgeon, hepatobiliary surgeon and radiological abdominal interventions. 


\section{MATERIAL AND METHOD}

For this study, scientific literature from PubMed was carried out from year 2005 to 2020 for the articles having anatomical variation of the hepatic artery in all publication. The relevant articles were also studied.

The following terminologies were used during research: "hepatic", "artery", "anatomic", and "variations". The entire relevant articles were also checked. The inclusion criteria of data were as following. 1) Original article or a review. 2) Studies based on Michel's classification. 3) Other type of classification, rare unreported anomalies or more commonly unclassified were not included. 4) The articles which were english in language.

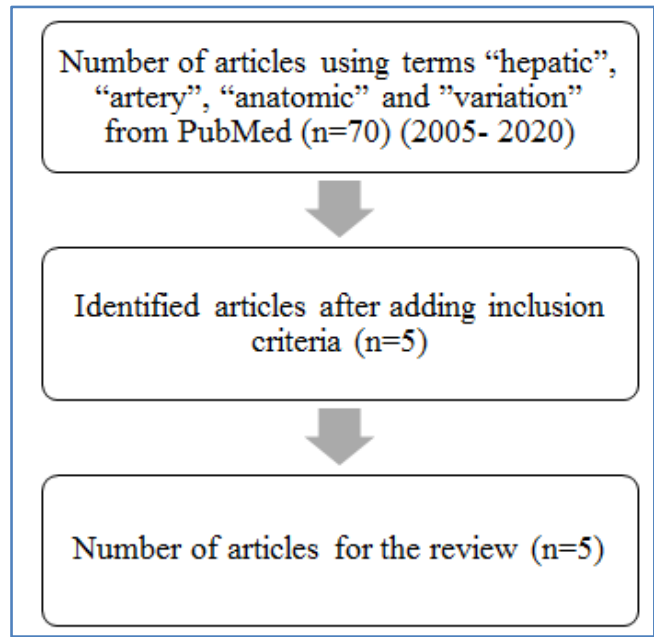

Chart: Flow chart showing the methodology of literature search

Table-1: Articles classification based on number and types of patients

\begin{tabular}{|l|l|l|}
\hline Authors & Number of patients & Type of patients \\
\hline Sebben GA et al. [9] & 45 & cadaver \\
\hline Fonseca-neto, olival cirilo lucena da et al. [10] & 479 & living \\
\hline Zagyapan R [11] & 152 & living \\
\hline Loschner C et al. [12] & 1297 & living \\
\hline Thangarajah A [13] & 200 & living \\
\hline
\end{tabular}

\section{RESULTS}

Out of 2173 cases, $1500(69.02 \%)$ showed type I normal pattern. $37(1.70 \%)$ cases displayed type II: a replaced LHA from the left gastric artery. Type III: a replaced RHA from the SMA was observed in 158 $(7.27 \%)$ cases. Type IV: replaced RHA and LHA were observed in $4(0.18 \%)$ cases.136 $(6.25 \%)$ cases displayed type V: an accessory LHA. $7(0.32 \%)$ of the subjects were found to have type VI: an accessory RHA. Type VII: accessory RHA and LHA and type VIII: a replaced RHA or LHA with other hepatic artery being an accessory one were not found. Type IX: the hepatic trunk as a branch of the SMA were $14(0.64 \%)$. $1(0.04 \%)$ was found in type X: the CHA from the left gastric artery.

Table-2: Results of recent study according to the Michels classification

\begin{tabular}{|l|l|l|}
\hline Michel's classification & Percentages & Number of person \\
\hline Type I normal pattern & $69.02 \%$ & 1500 \\
\hline Type II: a replaced LHA from the left gastric artery & $1.70 \%$ & 37 \\
\hline Type III: a replaced RHA from the SMA & $7.27 \%$ & 158 \\
\hline Type IV: replaced RHA and LHA & $0.18 \%$ & 4 \\
\hline Type V: an accessory LHA & $6.25 \%$ & 136 \\
\hline Type VI: an accessory RHA & $0.32 \%$ & 7 \\
\hline Type VII: accessory RHA and LHA; & 0 & 0 \\
\hline $\begin{array}{l}\text { Type VIII: a replaced RHA or LHA with other hepatic artery being } \\
\text { an accessory one; }\end{array}$ & 0 & 0 \\
\hline Type IX: the hepatic trunk as a branch of the SMA & $0.64 \%$ & 14 \\
\hline Type X: the CHA from the left gastric artery & $0.04 \%$ & 1 \\
\hline
\end{tabular}

\section{DISCUSSION}

As per available literature, trifurcation of tripus halleri was reported ranging from $60.0 \%$ to $94.2 \%$, and $\mathrm{Yi}$ et al reported $87.6 \%$ trifurcation in the subjects $(1,875 / 2141)[14]$. The study of the hepatic artery variations are abundant present in the literature. The anomalies of the hepatic arteries were replaced RHA in 11-21 \% and 3.8-10\% cases of replaced LHA.
Accessory RHA and LHA were $0.8-8 \%$ as per recent review [15].

Embryologically, the CT (celiac trunk) develops from six pairs of the ventral splanchnic vessels 1. Sub phrenic, 2.upper, 3.middle, 4.lower ventricular, 5.upper intestinal and 6.lower intestinal. Vascular anomalies or variation may results due to 
persistence of the longitudinal channels between the primitive vessels [16].

Anatomical variation in the hepatic artery is of great importance for the hepatic and pancreatic surgery, laparoscopic surgery as well as radiological intervention and penetrating injuries on the peri-hepatic area. With the help of computerized tomographic angiography, vascular anomalies of the hepatic artery can be delineate during preoperative procedure which help the surgeons [17]. An international classification of the principal anatomical variation of the vascular pattern of the liver was proposed by several authors, they are as follow, Adachi in 1928, Michels in 1966, Hiatt in 1994 and Abdullah in 2006. Although there are many variation which are not mention in above classification [18].

Michels studied 200 cadaveric dissections and identified 10 types of the hepatic arterial anatomical variations.(1)type I: normal pattern; (2) type II: a replaced LHA from the left gastric artery; (3) type III: a replaced RHA from the SMA; (4)type IV: replaced RHA and LHA; (5) type V: an accessory LHA; (6)type VI: an accessory RHA;(7) type VII: accessory RHA and LHA; (8)type VIII: a replaced RHA or LHA with other hepatic artery being an accessory one; (9)type IX: the hepatic trunk as a branch of the SMA; and (10) type $\mathrm{X}$ : the CHA from the left gastric artery[19].

Hiatt classified the hepatic artery into six categories: (1) Hiatt type I- the normal anatomy,(2) Hiatt type II- the LHA arising from the left gastric artery (3) Hiatt type III -the RHA arising from the SMA, (4) Hiatt type IV- every combination of a double replaced pattern, (5) Hiatt type $\mathrm{V}$ - the $\mathrm{CHA}$ originating as a branch of the SMA; and (5) the abnormality consisting of an isolated aortic origin of the CHA, Hiatt introduced it as type VI instead of including the rare variant with a CHA arising from the left gastric artery[20].

This study is based on 5 articles from the PubMed database and total 2173 cases were studied. We used the Michels classification because of its important in surgical aspects. Most common variation seen in this review is Type III: a replaced RHA from the SMA which is $158(7.27 \%)$ cases. These vessels are susceptible to damage during the pancreatic surgery. The type V: an accessory LHA (136 (6.25\%)) was second most common variation. The accessory LHA is accessory to the native LHA and runs along with its normal course. Injury to these vessels does not create any major problems [21]. Type II: a replaced LHA from the left gastric artery shows $37(1.70 \%)$.

In conclusion, variation in hepatic arterial pattern useful for various surgical procedures like hepatobiliary surgery, pancreatic surgery and gastric surgery. Accidental ligation or injury to these vessels may interrupt the blood supply. It also useful for radiological interventions. Further studies of nonclassified and rare anomalies are required.

\section{REFERENCES}

1. Standring, S. (2008). Gray's Anatomy (40th ed.).Edinburgh London: Churchill Livingstone.

2. Skandalakis, J.E. (2004). Skandalakis' Surgical Anatomy: The Embryologic and Anatomic Basis of Modern Surgery II. Athens, Greece: Paschalidis Medical Publication.

3. Hollinshead, W. H. (1971). Anatomy for Surgeons; the Thorax Abdomen and Pelvis. (2nd ed.). New York, NY, USA: Harper and Row.

4. Jones, R.M., Hardy, K.J. (2001). The hepatic artery: a reminder of surgical anatomy. Journal of the Royal College of Surgeons of Edinburgh, 46(3):168-170.

5. Michels, N.A. (1955). Blood supply and anatomy of the upper abdominal organs with a descriptive atlas. Philadelphia and Montreal: B. Lippincott Company, 134-183.

6. Bergman, R.A., Afifi, A.K., Miyauchi, R. (2015). Illustrated encyclopedia of human anatomic variations: Opus II: Cardiovascular system: Arteries: Abdomen: Variation in branch of celiac trunk: Hepatic artery, http://www.anatomyatlases.org.

7. Fischer, J.E., Bland, K.I. (2007). Mastery of Surgery. (5th Ed.) Philadelphia: Lippincott Williams \& Wilkins.

8. Yeo, C.J. (2007). Shackelford's surgery of the Alimentary Tract. (6th Ed.). Philadelphia: Saunders Elsevier.

9. Sebben, G.A., Rocha, S.L., Sebben, M.A., Parussolo Filho, P.R., Goncalve, S B.H. (2013). Variations of hepatic artery: anatomical study on cadavers. Rev Col Bras Cir, 40(3): 221- 226.

10. Foneseco-neto, Olival cirilo lucena da. (2017). Anatomical variation of hepatic artery: a study in 479 liver transplantations, ABCD, arq.bras.cir.dig. (online), 30(1): 35-37.

11. Zagyapan, R., kurkcuoglu, A., Bayraktar, A., Prelin, C., Aytekin, C. (2014). Anatomic variations of the celiac trunk and hepatic arterial sysem with digital substraction angiography. Turk $J$ Gastroenterol, 1:104-109.

12. Loschner, C., Nage, S.N., Kausche, S., Teichgraber, U. (2015). Hepatic arterial supply in 1297 CT-angiographies. Rofo, 187(4):276-282.

13. Thangarajah, A., Parthasarathy, R. (2016). "Celiac axis, common hepatic and hepatic artery variants as evidenced on MDCT angiography in south Indian population. Journal of Clinical and diagnostic research,10 (1):TC01-TC05.

14. Yi, S.Q., Terayama, H., Naito, M., Hirai, S., Alimujang, S., Yi, N., Tanaka, S. (2008). Absence of the celiac trunk: case report and review of the literature. Clin Anat, 21(4):283- 286. 
15. Shukla, P.J., Barreto, S.G., Kulkarni, A., Nagarajan, G., Fingerhut, A. (2010). Vascular anomalies encountered during pancreatoduodenectomy: do they influence outcomes? Ann Surg Oncol, 17(1):186-193.

16. Kosaka, M., Horiuchi, K., Nishida, K., Taguchi, T., Murakami, T., Ohtsuka, A. (2002).Hepatopancreatic arterial ring: bilateral symmetric typology in human celiaco-mesenteric arterial system. Acta Med Okayama, 56(5):245253.

17. Suzuki, T., Nakayasu, A., Kawabe, K., Takeda, H., Honjo, I.(1971). Surgical significance of anatomic variations of the hepatic artery. Am J Surg, 122(4):505-512.
18. Gurgacz, A.M., Horbaczewska, A., KlimekPiotrowska. W., Walocha, J. (2011). Variations in hepatic vascularisation: lack of a proper hepatic artery. Two case reports. Folia Morphol (Warsz), 70(2):130-134.

19. Michels, N.A. (1966). Newer anatomy of the liver and its variant blood supply and collateral circulation. Am J Surg, 112(3):337-347.

20. Hiatt, J.R., Gabbay, J., Busuttil, R.W. (1994). Surgical anatomy of the hepatic arteries in 1000 cases. Ann Surg, 220(1):50- 52.

21. Shukla, P.J., Barreto, S.G., Kulkarni, A., Nagarajan, G., Fingerhut A. (2010). Vascular anomalies encountered during pancreatoduodenectomy: do they influence outcomes? Ann Surg Oncol, 17(1):186-193. 